\title{
Using some natural sources to produce healthy Ketchup
}

\author{
Hanan G. Mohamed, Sahar A. Arafa and KH. M. Nematalla
}

Special Food and Nutrition Department, Food Technology Research Institute, Agricultural Research Center, Giza, Egypt.

Received: 07 Oct. 2020 / Accepted 05 Dec. 2020 / Publication date: 25 Dec. 2020

\begin{abstract}
The aim of this study was to produce a healthy ketchup by adding sumac water extract and pomegranate molasses to tomato ketchup formula instead of adding salt, vinegar, xanthan gum and modified starch at different concentrations $(1 \%, 2 \%, 3 \%, 4 \%$ and $5 \%$, respectively), to find the best level of addition to the ketchup formula without altering the characteristics of ketchup through studying the physicochemical parameters, chemical composition, sensory attributes and microbial activity of produced ketchup samples. It could be noticed that protein, ash, acidity, total and reducing sugars, total solids, water insoluble solids and total soluble solids contents of ketchup samples were significantly increased with the addition of sumac water extract and pomegranate molasses from $1 \%$ to $5 \%$ levels, respectively, while moisture content was significantly decreased compared with control sample. Ketchup sample made with sumac water extract at $2 \%$ level showed the lowest viscosity among other samples as a result of dilution, while viscosity was significantly increased with increasing sumac water extract and pomegranate molasses from $1 \%$ to $5 \%$ levels. Adding sumac water extract and pomegranate molasses to ketchup formula has resulted in changes in color parameters in the final product in relative to control sample. Samples formulated with sumac water extract and pomegranate molasses at $2 \%$ and $5 \%$ levels were considered of high quality from the viewpoints of color. It was found that sensory evaluated ketchup sample containing sumac water extract and pomegranate molasses at $4 \%$ level exhibited the highest overall acceptability score and was significantly different compared with other samples followed by samples containing $3 \%$ and $5 \%$ levels which were insignificantly differed compared with each other. It was observed that lower microbial activity was recorded in ketchup samples at zero time of storage, then total bacterial, and yeasts and molds counts were gradually increased in ketchup samples stored at $5^{\circ} \mathrm{C}$ from 0 to 12 weeks of storage. Also sumac water extract showed antibacterial activity against pathogenic bacteria. So, salt, vinegar, xanthan gum and modified starch could be replaced by sumac water extract and pomegranate molasses in ketchup formula to prepare an accepted ketchup product with satisfied quality attributes.
\end{abstract}

Keywords: sumac leaves water extract, pomegranate molasses, tomato ketchup, viscosity, color, quality attributes

\section{Introduction}

Tomato (Lycopersicon esculentum Mill.) is one of the most important agricultural crops among fresh vegetables in most countries in the world. The fruits are raw or cooked eaten. It is most popular as salad in the raw state and is made into soups, juice, ketchup, pickles, sauces, puree, paste, powder and other products. Its consumption has increased in the last few years and it was estimated that $35 \%$ of raw tomatoes are consumed as sauces, $18 \%$ as tomato paste, $17 \%$ as canned tomatoes, $15 \%$ are transformed into juices and 15\% into ketchup (Raiola et al., 2014 and Wasim and Singh, 2015). Tomato contains $94-95 \%$ water and 5 - 6\% organic compounds of which almost $1 \%$ is seeds and skin. Tomato consumption has been demonstrated to possess health benefits because of its rich content of bioactive phytonutrients such as lycopene, $\beta$-carotene, vitamins $\mathrm{E}$ and $\mathrm{C}$, phenolics, organic acids and flavonoids. Tomatoes contain substantial amount of minerals, sugars, amino acids and dietary fibers. It is a rich source of iron and phosphorus and also a very rich source of lycopene in the human diet. Among all dietary carotenoids, lycopene has the highest antioxidative properties. Tomatoes protect against prostate cancer, cardiovascular diseases and neurodegenerative diseases, which is provided by lycopene, antioxidants and phytochemicals in the fruit (Khokhar, 2013 and Trivedi and Patel, 2015). 
Ketchup is one of the most popular tomato products in the global market which requires limited equipments and simple processing. It is easy to use and is a low-calorie product. In the production process, thickening agents are used for their ability to act as water binding and bodying agents, i.e., modified starch, guar gum, xanthan gum, carboxymethyl cellulose to increase the consistency and prevent serum separation in ketchup (Mert, 2012). These hydrocolloids have not only an effective control over syneresis (Sahin and Ozdemir, 2007), but also threatens man's health because the combination between xanthan gum and modified starch in ketchup processing could produce veniline, a compound has carcinogenic effect (Sheftel, 2001). Therefore, it is necessary to find other substances to replace hydrocolloids and modified starch in products to avoid these defects.

The usage of spices has significantly increased because of its preservative role and inhibitory effect against microbial contamination. The usage of herbs in large quantity leads to high flavor and texture when used in the commodities (Sameer et al., 2014).

Sumac is herbal plant used as a spice in powder form and has purple or red color, could be added to food because of its good sour taste to improve the taste of foods. Sumac contains tannins, acetic acid which has antibacterial and antiviral effects, gallic acid, omega-3 fatty acids, citric acid, antioxidants and volatile oils with antifungal and antibacterial effects, i.e., geraniol, pornio, carvacol and thymol. The effect of powdered sumac leaves extract was studied on bacterial strains (gram positive or negative) and on yeasts. The results showed that, this extract has a powerful inhibitory effect against Bacillus cereus and Helicobacter pylori more than on yeasts. It has strong antioxidant effect due to its high content of polyphenols (Celikel and Kavas, 2008). Sumac could be added to tomato ketchup instead of salt and vinegar because it gave strong sour taste which could replace salt and the food taste still be acceptable to avoid the health problems of salt and vinegar, i.e., increasing blood pressure, increasing body weight, increasing acidity, stomach ulcers and have harmful effect on liver and pancreas. Sumac has dark red color which not change ketchup appearance and could be used as a preservative because of its antibacterial and antifungal effects.

Pomegranate molasses is a thick syrup made from cooked down pomegranate juice, which is a slightly astringent, sweet sour condiment that is deep and dark in color (Maskan, 2006). Pomegranate molasses could be added to tomato ketchup to increase viscosity and consistency because it has high viscous properties instead of hydrocolloids and modified starch. It also added a strong red color to tomato sauce because it contains red pigments and has high nutritional value, anti-oxidants and vitamins to avoid the harmful effect of hydrocolloids and modified starch.

Escherichia coli, Staphylococcus aureus and Bacillus cereus are food borne pathogens and are also associated with food spoilage. Staphylococcus aureus and Bacillus cereus are causatives of food poisoning due to intoxication as both produce enterotoxins. Both these organisms can also colonize the intestinal, mucosa and cause chronic diarrhea. Escherichia coli is generally regarded as part of the normal flora in the human intestine and are causatives of intestinal infection. However, prevention of the growth of these organisms are of great importance (Lazreg-Aref et al., 2012).

The aim of this study was to produce healthy ketchup by adding sumac water extract and pomegranate molasses to tomato ketchup formula instead of adding salt, vinegar, xanthan gum and modified starch at different concentrations $(1 \%, 2 \%, 3 \%, 4 \%$ and $5 \%$, respectively), to find the best level of addition to ketchup formula without altering the characteristics of ketchup through studying the physicochemical parameters, chemical composition, sensory attributes and microbial activity of produced ketchup samples.

\section{Materials and Methods}

\section{Materials:}

Tomato (Lycopersicon esculentum Mill), pomegranate fruit (Punica granatum L.) and sumac leaves powder (Rhus Coriaria) were purchased from a local market, Giza, Egypt. Tomato and pomegranate fruit were washed with tap water to remove dust and diseased fruits were discarded. All chemicals and reagents used were purchased from dealer of Sigma Chemical Company (St. Louis, MO, USA) at Egypt. 


\section{Methods:}

\subsection{Preparation of pomegranate molasses:}

Pomegranate molasses was prepared according to the method described by Sahar (2013) by using pomegranate seeds to extract pomegranate juice.

\subsection{Preparation of sumac leaves water extracts:}

Sumac water extract was prepared by overnight macerating $250 \mathrm{~g}$ sumac leaves powder in boiling distilled water (1L) to extract all chemical and biological constituents in the leaves, then filtered to obtain the water extract.

\subsection{Preparation of ketchup samples:}

Ketchup samples were prepared by mixing tomato juice, sucrose $5 \%$, spices (garlic and onion powders) $1 \%$, salt $2.5 \%$ and vinegar $6 \%$ without any additives, i.e., hydrocolloids and modified starch (homemade control ketchup sample) according to the method of Juszezak et al., (2013). Sumac water extract $(2 \%)$, pomegranate molasses $(2 \%)$, sumac water extract + pomegranate molasses $(1: 1 \mathrm{v} / \mathrm{v})$ at different concentrations $(1 \%, 2 \%, 3 \%, 4 \%$ and $5 \%$, respectively) were added to ketchup formula depending on panel test instead of salt, vinegar, xanthan gum and modified starch. The ingredients were mixed then heated for 4 to $5 \mathrm{~min}$ at $100^{\circ} \mathrm{C}$. The mixture was further left to boil at the same temperature for 25 to 30 min with stirring. The product (ketchup) obtained was further cooked at a lower temperature until a desirable thickness was obtained. After cooling, ketchup samples were packed into glass containers and stored in refrigerator up to analysis.

\subsection{Chemical analysis of ketchup samples:}

Moisture, protein, ash, titratable acidity, total and reducing sugars contents were determined in ketchup samples following the standard methods of AOAC (2005).

\subsection{Physicochemical parameters of ketchup samples:}

Total solids (TS) were determined using a vacuum oven at $70^{\circ} \mathrm{C}(8 \mathrm{hr})$. The water insoluble solids (WIS) were measured by adding $20 \mathrm{~g}$ of sample to boiling water for extraction the soluble solids. The mixture was centrifuged, and the supernatant filtered repeatedly until it had reached a refractive index of about zero. The residue (WIS) was dried in an oven at $100^{\circ} \mathrm{C}$ for $16 \mathrm{hr}$. (Bayod et al., 2008). Total soluble solids were determined by using an Abbe refractometer (Bellingham Stanley Limited) at $20^{\circ} \mathrm{C}$ using Brookfield Ddigital Rheometer, model HA DVIII Ultra (Brookfield Engineering Laboratories INC) and expressed in ${ }^{\circ}$ Brix, while $\mathrm{pH}$ was measured by means of a $\mathrm{pH}$ meter (Jenway, Staffordshire, United Kingdom). The viscosity of ketchup samples was measured at $20^{\circ} \mathrm{C}$ in a controlled stress rheometer equipped with a four-blade vane in order to eliminate the slip phenomenon. The vane was carefully loaded at stresses below $0.8 \mathrm{~Pa}$., special care was taken to minimize air inclusions in the sample. ACR-300 Chroma meter (Minolta, Osaka, Japan) was used for color measurements. The instrument was calibrated with a white standard tile $\left(L^{*}=97.43, a^{*}=-\right.$ $\left.0.01, b^{*}=1.64\right)$. A glass beaker containing the sample was placed below the light source. The color values $\mathrm{a}^{*} / \mathrm{b}^{*}$ of 1.9 and above are indicative of an excellent color, while values below 1.8 are considered unacceptable (Intelmann et al., 2005).

\subsection{Microbiological activity of ketchup samples:}

Microbiological tests including total bacterial counts, yeasts and molds, spore forming bacteria, Staphylococcus aureus and Bacillus cereus were determined in ketchup samples at 0, 2, 4, 6, 8, 10 and 12 weeks of storage at $5^{\circ} \mathrm{C}$ according to the methods of ISO (2008). Antimicrobial activity of sumac water extract was tested against 4 typed strains of bacteria using the agar well diffusion method as recommended by NCCLS (2003). The typed strains tested were two Gram positive (Bacillus cereus ATCC6538 and Staphylococcus aureus ATCC25923) and the others were Gram negative (E. coli ATCC25922 and Salmonella typhimurium ATCC9027). The cultures of strains used in this study were obtained from Microbiological Resources Centre (MIRCEN), Faculty of Agriculture, Ain Shams University, Cairo, Egypt. Bacterial strains were inoculated into Mueller Hinton broth (Difco) and incubated at $37^{\circ} \mathrm{C}$ for $24 \mathrm{~h}$. The cultures were subjected to three successive $24 \mathrm{~h}$. transfers before use. 


\subsection{Sensory evaluation of ketchup samples:}

Sensory evaluation of ketchup samples was carried out by ten well- trained panelists from Special Food and Nutrition Department, Food Technology Research Institute, Giza, Egypt. Each ketchup sample was subjected to evaluation with respect to its textural and sensorial properties including: color, taste, texture and flavor using semi-structured scales scoring $(1=$ lowest quality to $5=$ highest quality) which are adapted from Tornberg et al. (2005).

\section{Statistical analysis:}

The standard analysis of variance procedure in completely randomized design was applied for the present data according to Gomez and Gomez (1984). Experiments were carried out in triplicate and the results are expressed as mean values with standard deviation. Least significant difference test was done. The level of statistical significance was set at $p \leq 0.05$.

\section{Results and Discussion}

\section{Chemical composition of ketchup samples:}

Data presented in Table (1) showed the chemical composition of ketchup samples made from tomato juice with garlic, onion, salt, vinegar and sugar (homemade control ketchup sample) and ketchup samples with the addition of sumac water extract (2\%), pomegranate molasses $(2 \%)$, sumac water extract + pomegranate molasses $(1: 1 \mathrm{v} / \mathrm{v})$ at different concentrations $(1 \%, 2 \%, 3 \%, 4 \%$ and $5 \%$, respectively) instead of adding salt, vinegar, hydrocolloids and modified starch. It could be noticed that protein, ash, titratable acidity, total sugars and reducing sugars contents of ketchup samples were significantly increased with increasing the addition of sumac water extract and pomegranate molasses from $1 \%$ to $5 \%$ levels, respectively, while moisture content was significantly decreased compared with control ketchup sample.

Table 1: Chemical composition of ketchup samples (\%).

\begin{tabular}{lcccccc}
\hline Samples & Moisture & Protein & Ash & Acidity & Total sugars & $\begin{array}{c}\text { Reducing } \\
\text { sugars }\end{array}$ \\
\hline Control & $90.40^{\mathbf{a}} \pm 0.25$ & $1.80^{\mathbf{b}} \pm 0.23$ & $1.61^{\mathbf{d}} \pm 0.09$ & $1.76^{\mathbf{f}} \pm 0.64$ & $16.26^{\mathbf{c}} \pm 0.35$ & $6.54^{\mathbf{e}} \pm 0.11$ \\
S2 & $89.17^{\mathbf{b}} \pm 0.21$ & $1.74^{\mathbf{c}} \pm 0.30$ & $1.02^{\mathbf{e}} \pm 0.03$ & $1.64^{\mathbf{g}} \pm 0.50$ & $14.15^{\mathbf{d}} \pm 0.21$ & $5.85^{\mathbf{f}} \pm 0.06$ \\
$\mathbf{P 2}$ & $87.80^{\mathbf{c}} \pm 0.17$ & $1.81^{\mathbf{a}} \pm 0.25$ & $1.66^{\mathbf{c}} \pm 0.06$ & $1.85^{\mathbf{e}} \pm 0.53$ & $16.72^{\mathbf{b}} \pm 0.26$ & $6.53^{\mathbf{d}} \pm 0.10$ \\
$\mathbf{S}+\mathbf{P 1}$ & $89.29^{\mathbf{b}} \pm 0.23$ & $1.83^{\mathbf{a}} \pm 0.27$ & $1.69^{\mathbf{b}} \pm 0.07$ & $2.21^{\mathbf{d}} \pm 0.51$ & $16.66^{\mathbf{a}} \pm 0.30$ & $6.71^{\mathbf{c}} \pm 0.13$ \\
$\mathbf{S}+\mathbf{P 2}$ & $86.72^{\mathbf{d}} \pm 0.19$ & $1.85^{\mathbf{a}} \pm 0.24$ & $1.71^{\mathbf{b}} \pm 0.05$ & $2.38^{\mathbf{c}} \pm 0.45$ & $17.11^{\mathbf{a}} \pm 0.37$ & $6.84^{\mathbf{c}} \pm 0.16$ \\
$\mathbf{S}+\mathbf{P 3}$ & $85.55^{\mathbf{e}} \pm 0.15$ & $1.89^{\mathbf{a}} \pm 0.26$ & $1.73^{\mathbf{b}} \pm 0.03$ & $2.54^{\mathbf{b}} \pm 0.47$ & $17.36^{\mathbf{a}} \pm 0.23$ & $7.15^{\mathbf{b}} \pm 0.12$ \\
$\mathbf{S}+\mathbf{P 4}$ & $82.66^{\mathbf{f}} \pm 0.16$ & $1.91^{\mathbf{a}} \pm 0.33$ & $1.75^{\mathbf{a}} \pm 0.07$ & $2.63^{\mathbf{a}} \pm 0.43$ & $17.45^{\mathbf{a}} \pm 0.32$ & $7.50^{\mathbf{a}} \pm 0.17$ \\
S+P5 & $79.63^{\mathbf{a}} \pm 0.11$ & $1.94^{\mathbf{a}} \pm 0.36$ & $1.80^{\mathbf{a}} \pm 0.08$ & $2.67^{\mathbf{a}} \pm 0.37$ & $17.68^{\mathbf{a}} \pm 0.43$ & $7.67^{\mathbf{a}} \pm 0.15$ \\
\hline
\end{tabular}

$* \mathrm{~S} 2=$ sumac water extract $(2 \%), \mathrm{P} 2=$ pomegranate molasses $(2 \%), \mathrm{S}+\mathrm{P} 1=$ sumac water extract $(1 \%)+$ pomegranate molasses $(1 \%), \mathrm{S}+\mathrm{P} 2=$ sumac water extract $(2 \%)+$ pomegranate molasses $(2 \%), \mathrm{S}+\mathrm{P} 3=$ sumac water extract $(3 \%)+$ pomegranate molasses $(3 \%), \mathrm{S}+\mathrm{P} 4=$ sumac water extract $(4 \%)+$ pomegranate molasses $(4 \%)$ and $\mathrm{S}+\mathrm{P} 5=$ sumac water extract $(5 \%)+$ pomegranate molasses $(5 \%)$.

$*$ Values are Mean $\pm \mathrm{SD}(\mathrm{n}=3)$.

Addition of sumac water extract at $2 \%$ level (S2) caused a significant reduction in protein, ash, acidity, total sugars and reducing sugars contents compared with other ketchup samples as a result of dilution of the sample containing sumac leaves water extract. The present results are in good agreement with the results mentioned by Torbica et al., (2014) who found that moisture content ranged from $67.42 \%$ to $79.02 \%$, while total sugar content ranged from $12.26 \%$ to $18.44 \%$ in ketchup samples. It was observed from the results that titratable acidity increased with the addition of sumac water extract and pomegranate molasses in ketchup samples which may be affected by the temperature and presence of sugar content in fruits and also influenced by the conversion of starch into sugar (Lum, 2011). The reason behind the increase in ash content of ketchup samples is described by Wali (2013) who reported that the increase in ash content might be attributed to the biochemical 
and structural changes during processing. High mineral contents are sometimes used to reduce growth of certain microorganisms and also have certain health benefits in the diet (Effah-Manu et al., 2013).

\section{Physicochemical parameters of ketchup samples:}

Table (2) showed the physicochemical parameters of ketchup samples including total solids, water insoluble solids, total soluble solids, $\mathrm{pH}$ and viscosity. It could be observed as mentioned in Table (1) that increasing the concentration of sumac water extract and pomegranate molasses in ketchup samples formula caused a significant increase in total solids and water insoluble solids showed the same pattern compared with control ketchup sample. Total solids and water insoluble solids in sumac water extract at 2\% level (S2) and pomegranate molasses (P2) ketchup Samples were lower than other ketchup samples (Table 2). Total solids content is a measure of the solid particles after concentration which might explain the increasing in total and water insoluble solids in ketchup samples with increasing concentration of sumac water extract and pomegranate molasses from $1 \%$ to $5 \%$. Total soluble solids ( ${ }^{\circ}$ Brix $)$, a measure of the refractive index of ketchup samples, depends on the concentration and temperature of the solutes in solution and reflect the soluble sugars present in the samples also, the soluble solids content is important preserving factor. Increasing the concentration of sumac water extract and pomegranate molasses caused a slight increase in total soluble solids in ketchup samples. It was found that total soluble solids in ketchup samples were ranged from 14.6 to 32.7 ( ${ }^{\circ}$ Brix) (Jarmila et al., 2009).

Table 2: Physicochemical parameters of ketchup samples.

\begin{tabular}{lccccc}
\hline Samples & $\begin{array}{c}\text { Total solids } \\
(\mathbf{g} / \mathbf{k g ~ w b})^{\mathbf{a}}\end{array}$ & $\begin{array}{c}\text { Water insoluble solids } \\
(\mathbf{g} / \mathbf{k g} \mathbf{~ w b})^{\mathbf{a}}\end{array}$ & $\begin{array}{c}\text { Total soluble solids } \\
\left({ }^{(} \mathbf{B r i x}\right)\end{array}$ & $\mathbf{p H}$ & $\begin{array}{c}\text { Viscosity } \\
(\mathbf{c P})^{\mathbf{b}}\end{array}$ \\
\hline Control & $270.8^{\mathrm{e}} \pm 1.3$ & $16.3^{\mathrm{d}} \pm 0.7$ & $15^{\mathrm{c}} \pm 1.1$ & $3.92^{\mathrm{a}} \pm 0.01$ & $24200^{\mathrm{e}} \pm 141$ \\
$\mathbf{S 2}$ & $268.6^{\mathrm{f}} \pm 0.5$ & $14.3^{\mathrm{f}} \pm 0.3$ & $14^{\mathrm{c}} \pm 1.3$ & $3.81^{\mathrm{c}} \pm 0.03$ & $21300^{\mathrm{g}} \pm 125$ \\
$\mathbf{P 2}$ & $270.3^{\mathrm{e}} \pm 0.7$ & $15.7^{\mathrm{e}} \pm 0.4$ & $17^{\mathrm{b}} \pm 1.1$ & $3.84^{\mathrm{b}} \pm 0.01$ & $23900^{\mathrm{f}} \pm 141$ \\
$\mathbf{S}+\mathbf{P 1}$ & $271.8^{\mathrm{d}} \pm 1.2$ & $16.8^{\mathrm{c}} \pm 0.2$ & $17^{\mathrm{b}} \pm 1.8$ & $3.85^{\mathrm{b}} \pm 0.01$ & $25600^{\mathrm{d}} \pm 146$ \\
$\mathbf{S}+\mathbf{P 2}$ & $273.7^{\mathrm{c}} \pm 1.3$ & $17.2^{\mathrm{b}} \pm 0.5$ & $18^{\mathrm{b}} \pm 1.2$ & $3.75^{\mathrm{d}} \pm 0.02$ & $25900^{\mathrm{c}} \pm 143$ \\
$\mathbf{S}+\mathbf{P 3}$ & $274.3^{\mathrm{c}} \pm 1.1$ & $17.9^{\mathrm{a}} \pm 0.6$ & $18^{\mathrm{b}} \pm 1.8$ & $3.72^{\mathrm{e}} \pm 0.03$ & $26400^{\mathrm{b}} \pm 140$ \\
$\mathbf{S}+\mathbf{P 4}$ & $276.4^{\mathrm{b}} \pm 1.5$ & $18.1^{\mathrm{a}} \pm 0.7$ & $18^{\mathrm{b}} \pm 1.3$ & $3.62^{\mathrm{f}} \pm 0.01$ & $26700^{\mathrm{b}} \pm 144$ \\
$\mathbf{S}+\mathbf{P 5}$ & $279.3^{\mathrm{a}} \pm 1.3$ & $18.3^{\mathrm{a}} \pm 0.5$ & $20^{\mathrm{a}} \pm 1.6$ & $3.58^{\mathrm{g}} \pm 0.02$ & $27200^{\mathrm{a}} \pm 147$ \\
\hline
\end{tabular}

${ }^{\mathrm{a}} \mathrm{wb}=$ wet basis, ${ }^{\mathrm{b}}$ Brookfield viscometer, spindle no. 5 , speed at $10 \mathrm{rpm}$.

$*$ Values are Mean $\pm \mathrm{SD}(\mathrm{n}=3)$.

Among the parameters analyzed for the assessment of tomato ketchup quality, $\mathrm{pH}$ is a very important factor because acidity influences the thermal processing conditions required for producing safe products. Although the $\mathrm{pH}$ of mature tomatoes may exceed 4.6, tomato products are generally classified as acid foods $(\mathrm{pH}<4.5)$, which require moderate conditions of processing to control microbial spoilage and enzyme inactivation (Garcia and Barrett, 2006). Tomato products should have a $\mathrm{pH}$ value not exceeding 4.5, so the $\mathrm{pH}$ values were ranged between $3.58 \pm 0.02$ and $3.92 \pm 0.01$ in the present ketchup samples. There is an inverse relationship between $\mathrm{pH}$ values and titratable acidity which are in good agreement with our results.

The viscosity of tomato ketchup is a major quality component for consumer acceptance. Several parameters contribute to the flow behavior of tomato ketchup including degree of maturity, particle size and particle interactions, content of solids as well as temperature of processing. Tomato paste exhibits complex rheological behavior, i.e., it is a non-Newtonian, shear-thinning and time dependent fluid that shows an apparent yield stress (Abu-Jadayil et al., 2004). It could be noticed from data presented in Table (2) that, the viscosity of ketchup samples was significantly increased as the concentration of sumac water extract and pomegranate molasses increased from $1 \%$ to $5 \%$ levels, while the ketchup sample made from sumac water extract at $2 \%$ level (S2) showed the lowest viscosity among other samples as a result of high dilution. The semi-solid behavior of ketchup is not only influenced by the content and type of dispersed and soluble materials, but it is the result of a 
complex interaction between the pulp, soluble pectin, soluble solids, organic acids, the high volume concentration of particles and added hydrocolloids which replaced by pomegranate molasses in the present study and this may explain the increase in viscosity as a result of adding sumac water extract and pomegranate molasses at different concentrations to the ketchup formula (Koocheki et al., 2009). The viscosity increase was influenced by total solid content increase during processing as a function of juice dehydration or concentration which is in agreement with our results. The yield stress is defined as the minimum stress required by a material to initiate flow and values of yield stress increased with increasing hydrocolloids concentration (pomegranate molasses) and decreased by dilution and increasing temperature. So, the correction of the production process in the direction of dry matter increase or the correction of the formulation in the direction of pomegranate molasses increase could provide a viscosity of the final ketchup product as typical for the commercial ketchup packed in bottles.

\section{Color properties of ketchup samples:}

Data presented in Table (3) showed color parameters $\left(L^{*}, a^{*}\right.$ and $\left.b^{*}\right)$ values of ketchup samples formulated with replacement of vinegar, salt, hydrocolloids and modified starch by sumac water extract and pomegranate molasses at different concentrations. Sumac water extract and pomegranate molasses addition to the ketchup formulation resulted in changes in color parameters in the final product. Since $\left(L^{*}\right)$ value is a measure of the color in the light-dark axis, the reduction in this value indicates that the ketchup samples were turning darker. The decreases in $\left(\mathrm{L}^{*}\right)$ value seemed to be well correlated with the increases in the browning of food materials and pigment destruction (Ahmed et al., 2004).

Table 3: Color parameters of ketchup samples

\begin{tabular}{ccccc}
\hline \multirow{2}{*}{ Samples } & \multicolumn{3}{c}{ Color parameters } & \multirow{2}{*}{$\boldsymbol{a}^{*} / \boldsymbol{b}^{*}$ value } \\
\cline { 2 - 4 } & $\boldsymbol{L}^{*}$ & $\boldsymbol{a}^{*}$ & $\boldsymbol{b}^{*}$ & $1.95^{\mathrm{b}}$ \\
Control & $29.60 \pm 0.62$ & $21.46 \pm 0.53$ & $10.98 \pm 0.13$ & $1.02^{\mathrm{f}}$ \\
S2 & $25.84 \pm 0.71$ & $15.47 \pm 0.11$ & $15.15 \pm 0.10$ & $1.63^{\mathrm{e}}$ \\
P2 & $29.04 \pm 0.63$ & $18.46 \pm 0.58$ & $11.31 \pm 0.15$ & $1.60^{\mathrm{e}}$ \\
S+P1 & $31.15 \pm 0.24$ & $13.24 \pm 0.41$ & $8.29 \pm 0.11$ & $2.01^{\mathrm{a}}$ \\
S+P2 & $30.90 \pm 0.16$ & $17.03 \pm 0.46$ & $8.45 \pm 0.10$ & $1.70^{\mathrm{d}}$ \\
S+P3 & $29.30 \pm 0.75$ & $21.87 \pm 0.56$ & $12.95 \pm 0.16$ & $1.82^{\mathrm{c}}$ \\
S+P4 & $28.89 \pm 0.33$ & $16.44 \pm 0.33$ & $9.01 \pm 0.11$ & $1.90^{\mathrm{b}}$ \\
S+P5 & $27.45 \pm 0.37$ & $21.09 \pm 0.72$ & $11.35 \pm 0.13$ & \\
\hline
\end{tabular}

$*$ Values are Mean $\pm \mathrm{SD}(\mathrm{n}=3)$

*Numbers in the same column with the same letters were not significantly different at $p \leq 0.05$.

The lowest color parameters were achieved in ketchup samples with sumac water extract(S2) which it's $a^{*} / b^{*}$ value was the lowest among other ketchup samples and it was significantly different compared to other samples. The $\mathrm{a}^{*} / \mathrm{b}^{*}$ value is used as a quality specification for tomato products with values of 1.9 and above which are indicative of an excellent color, while values below 1.8 are considered unacceptable. It was found that ketchup sample formulated with sumac water extract $(2 \%)$, pomegranate molasses $(2 \%)$ and sumac water extract + pomegranate molasses at $1 \%$ level were achieved the lowest $\mathrm{a}^{*} / \mathrm{b}^{*}$ values compared with other ketchup samples. On the other hand, control ketchup sample and ketchup sample with sumac water extract and pomegranate molasses $(5 \%)$ were not significantly different compared with each other. Such samples were, also significantly different compared with ketchup sample formulated with sumac water extract and pomegranate molasses at $2 \%$ level. Consequently, these three ketchup samples were considered of good quality from the viewpoint of color. The decrease in color parameters of ketchup samples may be a result of the thermal treatment because extensive processing often goes along with the deterioration of the typical color. therefore, in order to maintain the native tomato color in ketchup processing samples must be stored at minimum period and temperatures. Exposure to sunlight and storage in oxygen containers permeable must be avoided. As a result, it can be said that all factors raising the intensity of redness in tomato ketchup, such as the appropriate tomato variety, extraction process, blanching, temperature and time should be applied to improve ketchup color (Kohan et al., 2016). Because 
pomegranate molasses is a concentrated product, color values are corresponded to dark, slightly red and blue in color.

\section{Sensory evaluation of ketchup samples:}

Sensory evaluation parameters of ketchup samples including texture, color, taste, flavor and overall acceptability were shown in Table (4). It could be noticed that increasing the concentration of sumac water extract and pomegranate molasses in ketchup samples caused an increase in sensory parameters, i.e., texture, color, taste, and flavor, respectively from $1 \%$ to $4 \%$ levels, while $2 \%$ sumac water extract ketchup sample recorded the lowest sensory attributes for color, taste, texture and flavor compared to ketchup samples replaced by sumac water extract and pomegranate molasses. Control ketchup sample achieved the lowest sensory parameters among other samples because it contained no hydrocolloids and modified starch (homemade ketchup). Lycopene is the color pigment of tomato, which is affected by the addition of sodium chloride (control ketchup sample) and heat treatment (Abreu et al., 2011). Increase in the concentration of spices beyond optimum amounts may reduce the taste ratings thus requiring optimization. Flavor and color changes have been reported to be the key parameters used to assess the quality changes of ketchup. Considering overall acceptability of ketchup samples, it was found that ketchup sample containing sumac water extract and pomegranate molasses (S+P4) was significantly different compared with other ketchup samples and exhibited the highest overall acceptability score followed by samples containing 3\% and 5\% sumac water extract and pomegranate molasses which were not significantly different compared with each other. Ketchup samples made from sumac water extract $(2 \%)$ and pomegranate molasses $(2 \%)$ were not significantly different between each other, but they were different compared with other ketchup samples. The lowest overall acceptability score was recorded for control homemade ketchup sample which was significantly different compared with other samples. Color and highly expressed spicy flavor and taste have been most important descriptors for evaluation among ketchup samples, therefore, tomato ketchup with increasing concentrations of sumac water extract and pomegranate molasses could be modified in order to be more viscous, red or Spicy according to consumer's preference. It should be taken into account that consumer's preference of a certain product is influenced by socioeconomic status, education, dietary habits, gender and age (Ali et al., 2015).

Table 4: Sensory parameters of ketchup samples.

\begin{tabular}{cccccc}
\hline Samples & Texture (5) & Color (5) & Taste (5) & Flavor (5) & Overall acceptability (20) \\
\hline Control & $3.07 \pm 0.32$ & $3.06 \pm 0.39$ & $2.82 \pm 0.21$ & $2.84 \pm 0.11$ & $11.79^{\mathrm{f}}$ \\
S2 & $3.48 \pm 0.75$ & $3.35 \pm 0.38$ & $2.93 \pm 0.16$ & $3.01 \pm 0.65$ & $12.77^{\mathrm{e}}$ \\
$\mathbf{P 2}$ & $3.65 \pm 0.43$ & $3.49 \pm 0.27$ & $2.99 \pm 0.85$ & $3.17 \pm 0.15$ & $13.30^{\mathrm{e}}$ \\
$\mathbf{S}+\mathbf{P 1}$ & $3.83 \pm 0.66$ & $3.61 \pm 0.17$ & $3.11 \pm 0.92$ & $3.38 \pm 0.56$ & $13.93^{\mathrm{d}}$ \\
$\mathbf{S}+\mathbf{P 2}$ & $3.96 \pm 0.60$ & $3.97 \pm 0.81$ & $3.18 \pm 0.39$ & $3.48 \pm 0.82$ & $14.59^{\mathrm{c}}$ \\
$\mathbf{S}+\mathbf{P 3}$ & $4.12 \pm 0.23$ & $4.05 \pm 0.62$ & $3.28 \pm 0.52$ & $3.70 \pm 0.39$ & $15.15^{\mathrm{b}}$ \\
$\mathbf{S}+\mathbf{P 4}$ & $4.53 \pm 0.77$ & $4.15 \pm 0.63$ & $3.68 \pm 0.78$ & $3.96 \pm 0.34$ & $16.32^{\mathrm{a}}$ \\
S+P5 & $4.19 \pm 0.12$ & $4.02 \pm 0.94$ & $3.49 \pm 0.25$ & $3.85 \pm 0.46$ & $15.55^{\mathrm{b}}$ \\
\hline
\end{tabular}

$*$ Values are Mean $\pm \mathrm{SD}(\mathrm{n}=3)$.

* Numbers in the same column with the same letters were not significantly

different at $\mathrm{p} \leq 0.05$.

\section{Microbial activity of ketchup samples:}

The effect of different concentrations of sumac water extract and pomegranate molasses added to ketchup samples on microbial activity including total bacterial counts and yeasts and molds at different storage periods $\left(0,2,4,6,8,10\right.$ and 12 weeks) at $5^{\circ} \mathrm{C}$ is shown in Figures (1) and (2), respectively. The results of total plate count in response to treatments and storage intervals showed that the lowest microbial activity was recorded in ketchup samples at zero time of storage, then total bacterial counts and yeasts and molds counts were increased in ketchup samples from 0 to 12 weeks of storage at $5^{\circ} \mathrm{C}$ and there was a gradual increase in microbial activity of samples during storage until 
it reached the highest microbial activity at 12 week of storage interval for all ketchup samples. The present results are in good agreement with the results mentioned by Nkhata and Ayua (2018) who observed that the low temperature used $\left(6^{\circ} \mathrm{C}\right)$ for storage of ketchup samples could not possibly significantly decrease microbial growth as psychrotrophs can still grow at this temperature. Chilled foods stored at temperatures near 0 to $6^{\circ} \mathrm{C}$ have been reported to have a longer shelf-life because of slower growth of microorganisms leading to delayed onset of spoilage (King and Cheethan, 2012). Microbial spoilage results in drastic effects on food quality as they can produce odor and gases as they ferment the food particles and spoilage in tomato sauce. It is mainly attributed to yeasts and molds as they can survive in acidic conditions. As the fact that all ketchup samples in the present study had a $\mathrm{pH}$ values less than 4.5 , it is more likely that yeasts and molds are the most prevalent microorganisms (Stewart and Amerine, 2012). It was found that mechanical damage during minimal processing enhance contamination by epithelial microflora and promote leaking of nutrients which are rich substances to microorganisms supporting the fast microbial development in contrast with intact tissues (Ayala-Zavala et al., 2008).

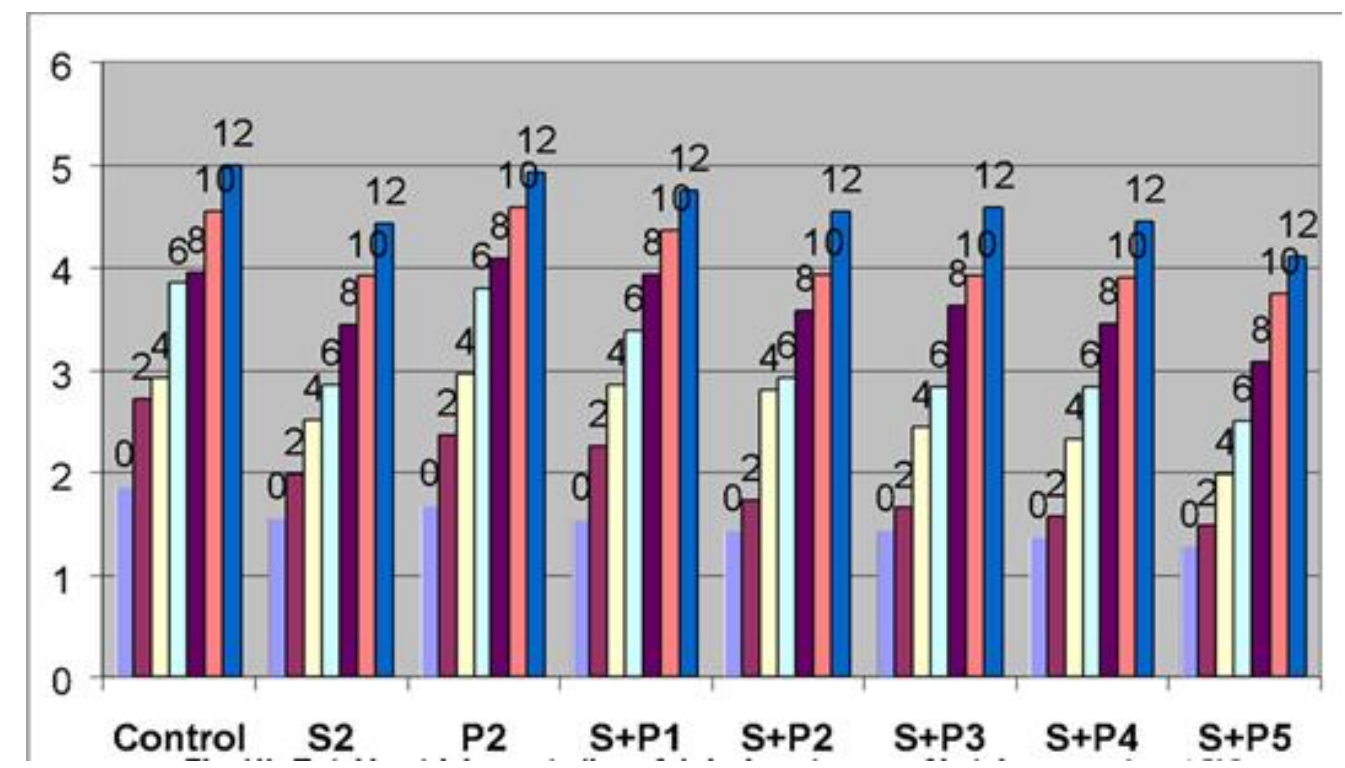

Fig. 1: Total bacterial counts $(\log \mathrm{cfu})$ during storage of ketchup samples at $5{ }^{\circ} \mathrm{C}$

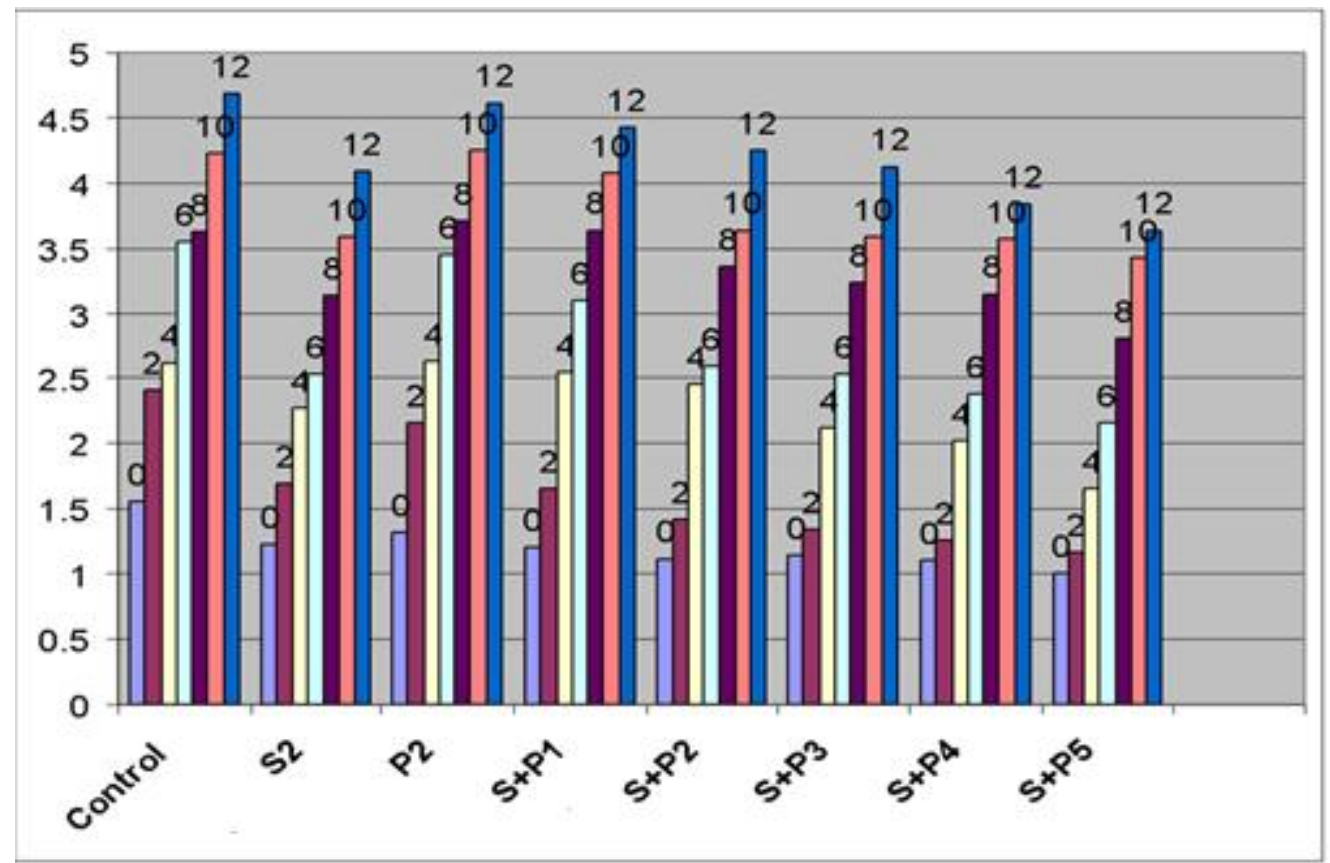

Fig. 2: Yeasts and molds counts $(\log \mathrm{cfu})$ during storage of ketchup samples at $5{ }^{\circ} \mathrm{C}$ 


\section{Effect of sumac water extract on growth of pathogenic bacteria.}

The agar well diffusion method was followed to determine the growth of pathogenic bacteria after incubation for $24 \mathrm{hr}$. at $37^{\circ} \mathrm{C}$ with sumac water extract at different concentrations, i.e., 1, 2, 3, 4 and $5 \%$. All plates were examined for any zones of growth inhibition and the diameters of these zones were measured in millimeters and presented in Table (5). Sumac water extract has shown antibacterial activity against pathogenic bacteria of Salmonella typhimurium (733) as more than $30 \mathrm{~mm}$ inhibition was obtained at 5\% level. Zone inhibition more than $33 \mathrm{~mm}$ was obtained for Escherichia coli (ATCC 25922) at 5\% level and at the same concentration, zone inhibition of Bacillus cereus (NCIM 2106) growth was more than $41 \mathrm{~mm}$, while for Staphylococcus aureus (ATCC 25923) the zone inhibition was more than $43 \mathrm{~mm}$ at $5 \%$ concentration of sumac water extract. Spore forming bacteria, Bacillus cereus and Staphylococcus aureus were estimated in control ketchup sample and other samples replaced by different concentrations of sumac water extract and pomegranate molasses at zero time of storage. Such bacteria were not detected in all samples, so they don't increase in samples, after storage for 12 weeks.

Table 5: Effect of sumac water extract on growth of pathogenic bacteria.

\begin{tabular}{ccccc}
\hline $\begin{array}{c}\text { Pathogenic bacteria } \\
\text { Sumac leaves water } \\
\text { extract (\%) }\end{array}$ & $\begin{array}{c}\text { Salmonella } \\
\text { typhimrium }\end{array}$ & $\begin{array}{c}\text { Escherichia } \\
\text { coli }\end{array}$ & $\begin{array}{c}\text { Bacillus } \\
\text { cereus }\end{array}$ & $\begin{array}{c}\text { Staphylococcus } \\
\text { aureus }\end{array}$ \\
\cline { 2 - 5 } & & Zone inhibition of growth (mm) & \\
\hline $\mathbf{1}$ & 12 & 16 & 15 & 17 \\
$\mathbf{3}$ & 15 & 19 & 20 & 21 \\
$\mathbf{4}$ & 19 & 22 & 24 & 38 \\
$\mathbf{5}$ & 25 & 28 & 35 & 43 \\
\hline
\end{tabular}

The sumac water extract used in the present study showed a profound activity against food borne pathogens and thus can be effective in controlling foodborne illness. Absence of Salmonella typhimrium, Staphylococcus aureus and Bacillus cereus in tomato ketchup samples reported in this study could be due to thermal treatment and cold storage of ketchup samples at $5^{\circ} \mathrm{C}$ which inhibit the growth and development of pathogens and spoilage microorganisms. However, thermal treatments applied during industrial preparation of tomato ketchup may involve various chemical reactions leading to the degradation of antioxidants which may lead to a lipid oxidation contributing to microconstituent instability. The presence of some aerobic mesophilic microorganisms, coliforms and anaerobic bacteria is related to the averments conditions and preparation methods of tomato ketchup (Fatima et al., 2015). The present results are in good agreement with Egyptian Standards (2005) for chemical and physicochemical parameters of tomato ketchup and with Egyptian Standards Codex (2015) for microbial and pathogenic bacterial growth in tomato ketchup, respectively.

\section{Conclusion}

The results which were obtained from this study indicated the possibility of using sumac water extract and pomegranate molasses instead of modified starch, xanthan gum, salt and vinegar in processing tomato ketchup to avoid the harmful effect of them. Also, sumac water extract showed profound activity against food borne pathogens which could be controlled food borne diseases. So, it could be concluded from the present study that sumac water extract and pomegranate molasses can be utilized to produce healthy, good quality and acceptable tomato ketchup.

\section{References}

Abreu, W.C., M.F.B. Barcelos, E.P. Silva, and E.V. Boas, 2011. Physical and chemical characteristics and lycopene retention of dried tomatoes subjected to different pretreatments. Rev. Inst., 70 (2): 168-174.

Abu-Jadayil, B., F. Banat, F. Jumah, and S. Hammad, 2004. A comparative study of rheological characteristics of tomato paste and tomato powder solutions. Inter. J. Food Proper., 7: 483-497.

Ahmed, J., U.S. Shivhare, and G.S.V. Raghavan, 2004. Thermal degradation kinetics of anthocyanin and visual color of plum puree. Eur. Food Res. Technol., 218: 525-528. 
Ali, I., I.M. Qazi, I. Ahmed, M.U. Khan, and S. Ullah, 2015. Influence of salt and spices on the overall acceptability and preservation of tomato cubes. Pak. J. Food Sci., 25 (3): 125-136.

AOAC, 2005. Association of Official Analytical Chemists, $17^{\text {th }}$ Edition (Helrich, K.). Arlington, Virgina, USA.

Ayala-Zavala, J.F., G. Oms-Oliu, and O. Martin-Belloso, 2008. Biopreservation of fresh-cut tomatoes using natural antimicrobials. Eur. Food Res. Technol., 226: 1047-1055.

Bayod, E., E. Pilman-Willars, and E. Tornberg, 2008. Rheological and structural characterization of tomato paste and its influence on the quality of ketchup. LWT, 41: 1289-1300.

Celikel, N. and G. Kavas, 2008. Antimicrobial properties of some essential oils against some pathogenic microorganisms. Czech. J. Food Sci., 26: 174-181.

Effah-Manu, L., I. Oduro, and A. Addo, 2013. Effect of dextrinized sweet potatoes on the physicochemical and sensory quality of infrared dried mango leather. J. Food Process. Technol., 4(5): 230-234.

Egyptian Standards (ES) 132-3/, 2005. Preserved Tomato Products, Part:3, Ketchup, ICS: 67.080.20, $1-9$.

Egyptian Standards Codex (ESC) 132-2/, 2015. Preserved Tomato Products, Part:2, Tomatoes Packed, pp. 1-14.

Fatima, D., K. Mebrouk, and H. Miloud, 2015. Biopreservation of tomato paste and sauce with Leuconostoc spp. metabolites. Afric. J. Food Sci., 9(6): 359-366.

Garcia, E. and D.M. Barrett, 2006. The quality control of tomato products. J. Food Process. Preserv., 30: 20-36.

Gomez, K.A. and A.A. Gomez, 1984. Statistical Procedure for Agricultural Research. John Wiley and Sons, Inc., USA.

Intelmann, D., D. Jaros, and H. Rohm, 2005. Identification of color optima of commercial tomato ketchup. Eur. Food Res. and Technol., 221(5): 662-666.

ISO 21527-1, 2008. Microbiology of food and animal feeding stuffs. Horizontal Methods for the Enumeration of Yeasts and Molds, Part 1: Colony Count Technique in Products with water activity greater than 0.95 .

Jarmila, L., K. Jolana, and K. Zlatica, 2009. The quality and authenticity markers of tomato ketchup. Acta Chimica Slovaca, 2(2): 88-96.

Juszezak, L., Z. Oezadly, and D. Galkowska, 2013. Effect of modified starches on rheological properties of ketchup. Food Bioprocess Technol., 6: 1251-1260.

Khokhar, K.M., 2013. Present status and prospects of tomatoes in Pakistan. Drying Technol., 16(3): 667-685.

King, R.D. and P.S.J. Cheethan, 2012. Food Biotechnolgy. $1^{\text {st }}$ Edition, Kindle edition, Springer Publishing Company. New York.

Kohan, N., B. Pakbin, R. Mahmoudi, and O. Fakhri, 2016. Effect of packaging material on color properties of tomato ketchup sauce. J. Appl. Packaging Res., 8(2): 10-16.

Koocheki, A., A. Ghandi, S.M.A. Razavi, S.A. Mortazavi, and T. Vasilijevic, 2009. The rheological preperties of ketchup as a function of different hydrocolloids and temperature. Int. J. Food Sci. Technol., 44: 596-602.

Lazreg-Aref, H., M. Mass, A.W. Fekih, M. Aouni, and K. Said, 2012. Chemical composition and antibacterial activity of a hexane extract of Tunisian caprifig latex from the unripe fruits of Ficus carica. Pharm. Biol., 50(4): 407-412.

Lum, M.S., 2011. Effects of hot water, submergence time and storage duration on quality of dragon fruit. J. Agric. Sci., 3(1): 146-152.

Maskan, M., 2006. Production of pomegranate juice concentrate by various heating methods: color degradation and kinetics. J. Food Engineer., 72: 218-224.

Mert, B., 2012. Using high pressure microfluidization to improve physical properties and lycopene content of ketchup type products. J. Food Engineer., 109: 579-587.

NCCLS, 2003. National Committee for Clinical Laboratory Standards. Methods for dilution antimicrobial susceptibility tests for bacteria that grow aerobically. $6^{\text {th }}$ Edition, Wayne, PA, 49.

Nkhata, S.G. and E.O. Ayua, 2018. Quality attributes of home made tomato sauce stored at different temperatures. Afric. J. Food Sci., 12(5): 97-103. 
Raiola, A., M.R. Rigano, R. Calafiore, L. Frusciante, and A. Barone, 2014. Enhancing the health promoting effects of tomato fruits for biofortified food. J. Mediat. Inflamm., 10(6): 1155-1162.

Sahar, A.A., 2013. Chemical and biological studies on some pomegranate products. Bull. Fac. Agric. Cairo Univ., 64: 396-408.

Sahin, H. and F. Ozdemir, 2007. Effect of some hydrocolloids on the serum separation of different formulated ketchup. J. Food Engineer., 81: 437-446.

Sameer, K.G., R. Ian, and M. Lisa, 2014. Enhancing consumer liking of law salt tomato soup over repeated exposure by herb and spice seasonings. Res. Rep. Sci. Direct. Appetite, 81: 20-29.

Sheftel, V.O., 2001. In Direct Food Additives and Polymers, Migration and Toxicology. CRC Press, Taylor and Francis, Boca Raton., 1066-1067.

Stewart, F.G. and M.A. Amerine, 2012. Introduction to food science and technology, $2^{\text {nd }}$ Edition, Academic Press, USA.

Torbica, A., M. Belovic, and T. Dapcevic, 2014. Nutritional, rheological and sensory evaluation of tomato ketchup with increased content of natural fibers made from fresh tomato pomace. Food and Bioproducts Process., 99(3): 485-496.

Tornberg, E., N. Carlier, E.P. Willers, and P. Muhrbeck, 2005. Sensory perception of salad dressings with varying fat content, oil droplet size and degree of aggregation. In E. Dickinson (Ed.), Food Colloids, 367-379.

Trivedi, T.K. and V.H. Patel, 2015. To study the effect of raw and processed tomato supplementation on plasma total antioxidant capacity. J. Med. Health Sci., 4(4): 38-43.

Wali, A.F., 2013. Information technology infrastructure and customer service delivery. British J. Market Stud., 1(2): 17-32.

Wasim, S.M. and J.P. Singh, 2015. Compositional alterations in tomato products during storage. Res. J. Chem. Environ., 19(2): 82-87. 